\title{
Enfoque interdisciplinar del discurso periodístico sobre la cultura española: un estudio del corpus en la prensa digital inglesa
}

Por: Dra. Beatriz Rodríguez Cuadrado ${ }^{1}$, Universidad Complutense de Madrid, España y Dr. Óscar O. Santos-Sopena ${ }^{2}$, Universidad Politécnica de Madrid, España, ORCID: 0000-0001-9505-5220

Recibido: 14 de setiembre, 2019.

Aceptado: 21 de octubre, 2019.

\section{RESUMEN}

La relevancia en los medios de comunicación es un elemento poco cuestionado por la sociedad. En este estudio se analiza el poder que ejerce a la hora de determinar actitudes ante acontecimientos socioculturales. Para ello, se ha establecido una correspondencia entre las teorías lingüísticas y las comunicativas, tomando los postulados conversacionales de Grice (1975) y la teoría de la agenda setting (McCombs, 1992, 1994, 1996, 2006). Como corpus se han seleccionado las noticias culturales sobre España en la edición digital The Guardian (2013-2014), para comprobar si se ha producido algún mal uso de estas o si, por el contrario, se ha llevado a cabo una comunicación efectiva. Se ha realizado un análisis cuantitativo-cualitativo y los resultados dan a conocer la imagen, no siempre imparcial, que ofrece este medio durante un período de crisis. Este artículo contribuye a profundizar sobre las implicaciones del discurso y el posible efecto cognitivo de la cobertura temática.

\section{ABSTRACT}

An interdisciplinary approach to journalistic discourse on Spanish culture: a corpus study in digital press in the UK

This research analyzes the power applies when determining the attitudes of a society before sociocultural events. A connection between linguistic and communication theories, applying the Grice's Conversational Maxims (1975) and the theory of agenda setting (McCombs 1992, 1994, 1996, 2006), has been used. In this study, all news published about Spain in The Guardian digital edition (2013-2014) was selected to check if there is any misappropriation or misuse of them or if a proper, effective, and truthful communication. To check the use of information from The Guardian a quantitative and qualitative analysis of the content of this news has been made. The results reveal that the image offered by this digital media during this specific period of economic crisis is not always impartial. This paper helps to divulge the implications of discourse and the possible cognitive effect of the thematic coverage of these types of news.

1 Beatriz Rodríguez es Doctora en Periodismo por la Universidad Complutense de Madrid. Posee un máster en Cultura Contemporánea en el Instituto Universitario Ortega y Gasset. Actualmente, es profesora en el Centro de Estudios Universitarios CEDEU, de la Universidad Complutense de Madrid. Contactos: brcuadrado@ucm. es y b.rodriguezcuadrado@cedeu.es.

2 Óscar O. Santos-Sopena es Doctor en Filología por la Universidad de Maryland, EE.UU., la Universidad Complutense de Madrid y la UNED. En la actualidad, es profesor ayudante Doctor en la Universidad Politécnica de Madrid, en el Departamento de Lingüística Aplicada a la Ciencia y a la Tecnología. Contactos: oscarsantossopena@gmail.com y oscar.santos.sopena@upm.es.

Beatriz Rodríguez Cuadrado y Òscar O. Santos-Sopena. Enfoque interdisciplinar del discurso periodístico sobre la cultura española: un estudio del corpus en la prensa digital inglesa. Revista Comunicación. Año 40, volumen 28, número 2, julio-diciembre, 2019. Instituto Tecnológico de Costa Rica. ISSN: 0379-3974 / e-ISSN1659-3820

\section{PALABRAS CLAVE:}

Discurso, comunicación, medios de comunicación de masas, opinión, lingüística aplicada, lengua y cultura, sociología cultural.

\section{KEY WORDS}

Discourse, communication, mass media, opinion, applied linguistics, language and culture, cultural sociology. 


\section{INTRODUCCIÓN}

El panorama creado por los medios digitales ha implicado la creación de nuevas prácticas en el mundo de la comunicación. No solo el contenido digital ha cambiado, para Marcos Recio también ha aparecido un nuevo lector que:

busca información útil, de calidad y con datos que le permitan reflexionar. Los lectores ya no quieren información. Disponen de miles de informaciones en los diferentes "aparatos" que usan cada día. Esperan, de los periódicos impresos y digitales, una visión que les lleve a crear su propia opinión y poder compartirla con otras personas (2014, p. 120).

Meso Ayerdi, Mendiguren Galdaspin y Rivero Santamarina (2015) señalan sobre la actual irrupción digital en las prácticas periodísticas que: "se están reinventado para responder a un escenario complejo, marcado por la actualización constante, la abundancia informativa, la mayor presencia de las audiencias en el proceso comunicativo y la innovación en formatos/soportes de consumo" (p. 164). Por lo tanto, teniendo en cuenta estos cambios en la recepción de la información, se ha considerado de especial relevancia el estudio de las nuevas prácticas periodísticas utilizadas por el diario británico The Guardian, en especial el uso del lenguaje. La selección de la edición digital de este rotativo de centroizquierda se debe a su larga trayectoria, desde 1821, y por ser un referente de información de calidad y prestigio tanto nacional como internacional. Rius señala este diario como "el gran periódico global" del que dice: "se ha convertido en una organización multiplataforma que, apuesta por el periodismo de datos y la visualización infográfica de la información, los contenidos multimedia y el uso intensivo de las redes sociales" (2016, p. 198). El peso de los lectores de su versión digital es más que notable; así, los datos proporcionados por Audit Bureau of Circulation ${ }^{4}$ muestran cómo en 2014, uno de los años objeto de estudio de esta investigación, la red de sitios web, The Guardian superó los 100 millones de navegadores mensuales por primera vez en el mes de marzo. Asimismo, se debe destacar que en el año 2013 se lanzó la edición digital de The Guardian en Australia, lo que supuso un aumento masivo de lectores.

A lo largo de los siglos XX y XXI, la cultura ha posicionado a España en un lugar privilegiado en el mundo debido a su capacidad de creación artística que se ha convertido en un factor clave para la difusión de su imagen en el exterior (Ferrer Montolíu, 2014). A su vez, Delgado Gómez-Escalonilla (2012) considera que la cultura y la lengua suponen un valor añadido a la proyección internacional de los países, además de aportarles beneficios económicos. También, sostiene que en ellas se encuentra la identidad y la cohesión entre los pueblos. Por ello, se ha considerado esencial estudiar el significado del lenguaje empleado en las noticias culturales relativas a España en la versión digital de The Guardian. Este análisis permite conocer la visión cultural propuesta por este medio en los años más complejos de la crisis financiera de principios de siglo XXI (2013-2014).

Este trabajo se basa en que los efectos del discurso de los medios de comunicación son trascendentales a la hora de crear una determinada opinión en los lectores. La visión que ofrecen los medios influye en la percepción de la sociedad, es decir, difunden, crean y modifican los marcos -frames- o modelos de conocimiento sobre el mundo (Fillmore, 2006). Por lo tanto, esta percepción de los acontecimientos va a depender de la elección de las noticias y la cobertura temática que el medio realice. Bien es sabido que el medio de comunicación no permanece imparcial ante determinados sucesos; a veces, su postura queda implícita o directamente manifiesta. En definitiva, el discurso que generan es capaz de determinar la adquisición, el aprendizaje y la modificación de la actitud o la creencia de sus lectores ante un hecho. Para medir estos posibles efectos, se ha hecho uso de las posibilidades que ofrece la lingüística computacional. Por ello, para la primera parte de este estudio se empleó la herramienta textual Sketch Engine (https://www.sketchengine.eu/) para conocer el tratamiento cuantitativo del léxico empleado. 


\section{ESTADO DE LA CUESTIÓN: UN ACERCAMIENTO A LAS TEORÍAS COMUNICATIVAS}

Debido a la crisis económica, política, social y cultural, ya mencionada anteriormente, la imagen deteriorada de los países mediterráneos influye en las relaciones socioculturales y en su proyección exterior. La función informativa va a depender de la elección del contenido y el lenguaje empleado en el discurso. Relacionado con el primer factor, encontramos las teorías de la agenda setting y del framing, que investigan cómo el tratamiento y la elección de la temática de las noticias pueden influir en la audiencia (Geer 2004).

En los años setenta del siglo XX, se desarrolla la teoría de la agenda setting que estudia la repercusión de la información proporcionada por los medios de COmunicación en la opinión pública (McCombs, 1992, 1994, 1996, 2006). Se podría decir que, según este postulado, aquello que los medios consideran más relevante para su agenda será lo más relevante para la opinión pública. Según McCombs (1994), se desarrolla en dos niveles, tal como aparece en la tabla 1, que se muestra a continuación:

\section{Tabla 1. Niveles de la agenda setting}

\begin{tabular}{lll}
\hline \multicolumn{1}{c}{ Niveles } & \multicolumn{1}{c}{ Primer nivel } & \multicolumn{1}{c}{ Segundo nivel } \\
\hline Objeto & $\begin{array}{l}\text { Los medios decidirán sobre } \\
\text { qué pensará la audiencia }\end{array}$ & $\begin{array}{l}\text { Los medios decidirán lo que } \\
\text { pensará la audiencia }\end{array}$ \\
\hline Repercusión/Peligro & Desinformación & Manipulación \\
\hline & Comprensión parcial & Prejuicios \\
\hline
\end{tabular}

Fuente: adaptada de McCombs (1994)

Cohen señala dónde reside el verdadero poder de la prensa: "The press may not be successful all the time in telling people what to think, but it is stunningly successful in telling its readers what to think about" (1963, p. 13). En estrecha relación con lo anterior, para la teoría del framing, un medio conforma marcos interpretativos en los lectores al enfatizar en la agenda determinados temas y aspectos de la noticia. Para la presente investigación, la capacidad de influencia que poseen estas teorías comunicativas a nivel cognitivo resulta fundamental: "Esta estrategia de los medios de comunicación puede tener efectos de tipo cognitivo, pues puede influir en los temas o asuntos que el público utiliza para generar sus propias reflexiones" (Muñiz, 2007, p. 103).

Algunos autores (Lazarsfeld y Merton, 1948; McCombs, 2006) señalan que es muy frecuente que un tema relevante para la agenda mediática pase a serlo también para la opinión pública, por lo que se habla de proceso de transmisión de la relevancia. McCombs se refiere a ello como una relación de causa y efecto, y sostiene que: "Los medios informativos establecen la agenda del público. Sitúan un tema en su repertorio para centrar su foco de atención y constituir así el inicio de la formación de la opinión pública" (2006, p. 25).

Los efectos de los medios de comunicación mediante estas teorías han sido también desarrollados por Nabi y Oliver, quienes sugieren que:

are part of the same broad tradition of research on how news can influence audiences through the choice of what stories to feature and how much prominence to give particular elements within reports. These news reports and their internal features are thought to shape the nature cognitive responses, the mechanism through which agenda- setting and framing effects occur (2009, p. 83).

Para esta investigación, se ha tomado el concepto de cultural agenda setting entendido como:

The main idea behind cultural agenda setting theory is that the transfer of salience from the media to the public also applies to the case 
of cultural products or, more broadly, cultural objects such as works of art, artists, and cultural organizations (Symeou et al. 2015, p. 733).

Precisamente estos productos culturales, noticias en este caso, ayudan a perpetuar una imagen cultural de España y de 'lo español' en el espacio cívico que es motivo de estudio en esta investigación.

Un acercamiento teórico a partir de los estudios culturales de la agenda setting promueve un componente transversal y multidisciplinar fundamental para esta investigación. Igualmente, la revisión de las noticias culturales sobre España en un medio de comunicación inglés aporta información sobre el contexto y el escenario cultural e híbrido de los procesos democratizadores de la información y suscita, a su vez, una cultura de masas y digital que se mide a través de la visibilidad de sus noticias:

For the first level of agenda setting, this implies that cultural objects that receive high levels of media visibility or media coverage acquire public salience. For the second level, cultural agenda setting suggests that the media also influence the attributes of various cultural objects. For example, through media valence, the positive, neutral, or negative tone the media adopt regarding a particular cultural object is then transferred to the public (Symeou, Bantimaroudis y Zyglidopoulos, 2015, p. 734).

De igual modo, los aspectos culturales genéricos y temáticos nos ayudan a entender la esencia básica de las relaciones sociales y marcan las tendencias socioculturales, cuestión que nos interesa recalcar con este estudio (Matthes, 2006, p. 423). Por lo tanto, los contextos socioculturales resultan esenciales a la hora de entender los aspectos culturales y sus noticias, las cuales son fuente de análisis en esta investigación: "Agenda setting theory applies to cultural contexts because in dealing with cultural objects, individuals have a high level of NFO, possibly even higher than in the political domain, because of certain peculiarities that pertain to the cultural sector" (Symeou et al. 2015, p. 734).

Como se ha tratado, el medio selecciona la temática que va a considerar beneficiosa para sus propios intereses. Sin embargo, el lenguaje que emplee va a ser decisivo para crear una idea en la mente del lector. Esta idea se encuentra presente en las siguientes palabras de Convoy: "Another advantage of considering newspaper language as a discourse is that it enables us to view news production and dissemination as creating new forms of power as well as new forms of access to representation" (2010, p. 10).

La combinación de los elementos sociales y lingüísticos en la comunicación, también ha sido abarcada en diferentes estudios (Fairclough, 1995; Bell, 1996; Van Dijk, 1999; Colleen, 2010; Convoy, 2010). Lippman (2003), creador del concepto de estereotipo, también analizó los efectos de la comunicación de masas sobre la opinión pública y su repercusión en la creación de los mapas cognitivos en la sociedad.

Tomando como referencia estas investigaciones multidisciplinares, en el presente trabajo se ha considerado de gran relevancia partir del planteamiento clásico de Grice (1975), enmarcado en una teoría pragmático-lingüística. Este autor postuló una serie de estrategias (las máximas conversacionales) que son las responsables de que la comunicación entre el emisor y el receptor sea o no efectiva. Se trataría, por tanto, de aplicar estas máximas al campo de la comunicación. El emisor es el medio y el receptor lo conforman sus lectores. 
Enfoque interdisciplinar del discurso periodístico sobre la cultura española: un estudio del corpus en la prensa digital inglesa

Tabla 2. Máximas conversacionales

\begin{tabular}{cccc}
\hline $\begin{array}{c}\text { Máxima de } \\
\text { CANTIDAD }\end{array}$ & $\begin{array}{c}\text { Máxima de } \\
\text { CALIDAD }\end{array}$ & $\begin{array}{c}\text { Máxima de } \\
\text { RELEVANCIA }\end{array}$ & $\begin{array}{c}\text { Máxima } \\
\text { de MODO }\end{array}$ \\
\hline $\begin{array}{c}\text { Haz tu contribución } \\
\text { a la conversación tan } \\
\text { informativa como sea } \\
\text { necesario }\end{array}$ & $\begin{array}{c}\text { No digas lo que creas } \\
\text { que es falso }\end{array}$ & Sé claro \\
$\begin{array}{c}\text { No hagas tu contribu- } \\
\text { ción más informativa } \\
\text { de lo necesario }\end{array}$ & $\begin{array}{c}\text { No digas aquello de } \\
\text { tengas seguridad }\end{array}$ & Sé relevante & $\begin{array}{c}\text { Evita la oscuridad de } \\
\text { la expresión }\end{array}$ \\
& & Evita la ambigüedad \\
\hline
\end{tabular}

Adaptada de Grice (1975)

Este estudio propone que estas máximas, a pesar de estar integradas en la pragmática, pueden ser aplicadas al periodismo. Esta vinculación la relacionamos con el estilo periodístico que propone Grijelmo (2017) y el poder que ejerce el periodista sobre la audiencia. La principal técnica lingüística de la insinuación en los medios informativos parte de la yuxtaposición: es decir, una idea situada junto a otra sin que se explicite relación sintáctica o semántica entre ambas. Pero esa contigüidad obliga al lector a deducir una vinculación (Grijelmo 2017). Para este periodista, no solo se valen de la insinuación, también de la inversión de la relevancia. Además, manifiesta que los medios frecuentemente informan de aspectos secundarios que logran un valor clave en la opinión pública. Según este autor, ello iría en detrimento de lo que verdaderamente tiene interés general y social.

Siguiendo con el enfoque social del discurso de los medios, Taylor (2009) considera que estos tienen una función central en el proceso de construcción social de la realidad al intervenir en la creación de la opinión de los lectores:

journalists select and create news, and readers select and consume newspapers which reflect their world view. This view of the press as both reflecting and creating social reality may also be observed, at a different level, in the social view of language itself [...] (p. 3).

Esta idea entra en consonancia con el tema de este artículo ya que gracias a sus noticias, The Guardian genera imágenes mentales sobre la cultura española en los lectores. Después de esta breve revisión bibliográfica, se presentan a continuación la metodología del estudio, los hallazgos obtenidos y las principales conclusiones a las que se ha llegado.

\section{METODOLOGÍA Y DESCRIPCIÓN DE LOS RESULTADOS}

El uso de la informática aplicada al análisis del lenguaje ha derivado en el desarrollo de distintas herramientas textuales que ofrecen grandes posibilidades para el análisis crítico del discurso. Debido a la naturaleza de esta investigación se consideró necesario emplear la herramienta computacional denominada Sketch Engine ${ }^{5}$ (2003), la cual proporciona información sobre palabras y grupos de palabras. Los resultados del programa aparecen estructurados en los siguientes niveles: del léxico-gramatical se han obtenido las concordancias en relación con los lemas principales ("Spain" y "Spanish"). A su vez, en el nivel de expresiones compuestas o "phrases" se han recogido las combinaciones de palabras, así como las búsquedas de patrones y concordancias paralelas. Además, mediante los criterios de la búsqueda establecidos para este estudio, se ha llevado a cabo la extracción de palabras clave y se obtuvieron listas de expresiones compuestas frecuentes, y se han introducido los lemas "Spain" o "Spanish" unidos a "at the beginning of...", "in relation to the...", etc.

5 En este punto, es relevante señalar que esta herramienta ha sido utilizada en la elaboración de importantes diccionarios de las editoriales Cambridge University Press y Oxford University Press, entre otras. 
A la hora de fijar el corpus de este estudio, se tuvieron en cuenta las consideraciones de Parodi (2010) quien entiende que, en la actualidad, para que un corpus sea factible debe cumplir estas características:

- Recolección de textos en entornos naturales.

- Explicitud de los rasgos definitorios y compartidos por los textos constitutivos.

- Formato final de tipo digital plano (*. txt) para cada texto o documento.

- Tamaño, preferentemente, extenso.

- Respeto a principios ecológicos.

- Etiquetaje computacional semi-automático, de naturaleza morfosintáctica u otra para cada texto.

- Disponibilidad a través de los medios computacionales.

- Acceso a visualización completa de los textos que lo componen, en formato plano.

- Búsqueda de principios de proporcionalidad o representatividad (posiblemente estadística).

- Sustento o procedencia inicial especificada.

- Identificación de una organización en torno a temas, tipo de textos, registros, géneros, etc.

- Registro de datos cuantitativos que permita la comparación y posible normalización de cifras (Parodi, 2010, p. 26).

Por lo tanto, en esta investigación se han seleccionado todas las noticias que presentaran en el titular las palabras "Spain" y "Spanish" en la edición digital The Guardian, durante los años 2013 y 2014, para comprobar si se ha producido alguna violación de las máximas abordadas anteriormente (cantidad, verdad, claridad y relevancia). La decisión de este criterio léxico de selección se debe a que el acceso a las noticias digitales se puede obtener únicamente si el lector pulsa el hipervínculo del titular. Recuérdese que por lo general, tales encabezados se convierten en una llamada de atención determinante para que se produzca la lectura completa de la noticia.
Como objetivo principal se pretende evaluar la cobertura sobre la cultura española en este medio de comunicación a partir de directrices propias de la lingüística aplicada y la computacional.

En función de este objetivo principal, se formularon los siguientes objetivos específicos:

(1) Identificar y cuantificar las noticias culturales en este diario en 2013-2014.

(2) Conocer la representación cultural de España en este diario en 2013-2014.

(3) Medir el proceso de relevancia entre la agenda mediática (causa y efecto) y las máximas conversacionales en las noticias seleccionadas.

Las noticias divulgadas por The Guardian se han sometido a un análisis léxico-semántico, tanto de los titulares como del contenido. La muestra la constituye un corpus formado por 216 noticias que contenían 122.143 palabras. La segmentación de los datos del corpus se presenta en la siguiente tabla:

Tabla 3. Número de noticias del corpus

\begin{tabular}{|c|c|c|}
\hline \multicolumn{3}{|c|}{ ESPAÑA } \\
\hline Año & Lema & Núm de noticias \\
\hline \multirow[t]{2}{*}{2013} & Spain & 44 \\
\hline & Spanish & 43 \\
\hline \multirow[t]{2}{*}{2014} & Spain & 68 \\
\hline & Spanish & 61 \\
\hline Núm & e palabras & 122.143 \\
\hline
\end{tabular}

Fuente: elaboración propia.

En primer lugar, es indispensable dar cuenta de la frecuencia de los lemas específicos para la extracción automática, es decir, la unidad autónoma y semántica que constituye parte del léxico de este corpus. La siguiente tabla muestra la frecuencia de los lemas referidos a España en el corpus: 
Tabla 4. Frecuencia de los lemas Spain/Spanish

\begin{tabular}{lc}
\hline \multicolumn{2}{c}{ ESPAÑA } \\
\hline \multicolumn{1}{c}{ PALABRAS } & FRECUENCIA \\
\hline SPAIN & 860 \\
\hline SPANISH & 766 \\
\hline SPANIARDS & 83 \\
\hline TOTAL & 1.709 \\
\hline
\end{tabular}

Fuente: elaboración propia

Durante los dos años de estudio y, según los criterios de selección marcados en este trabajo, se han hallado 49 noticias cuya temática está relacionada con la cultura española. Tras su lectura pormenorizada, se han seleccionado 26 noticias, las cuales incumplían alguna de las máximas descritas. Para proporcionar un mayor rigor científico a este análisis, se han establecido unos parámetros que faciliten la evaluación de los posibles incumplimientos de las máximas conversacionales en la agenda del diario. Si bien una objetividad absoluta en este tipo de análisis discursivos es difícil de conseguir, se han empleado una serie de criterios para evitar en lo posible juicios subjetivos.

Se considerará que la máxima de la Cantidad no se ha cumplido en la elaboración de la noticia cuando: (1) El número de palabras no está justificado por la trascendencia de la noticia sobre la cultura española y (2) La repetición de la noticia parece evidenciar una importancia que para la cultura española no consta. Esto se ha evaluado tanto por exceso como por la falta de palabras/noticias.

La violación de la máxima de la Calidad se ha identificado en aquellas noticias cuya información queda de una dudosa veracidad. Se constata mediante una falta de documentación, la calidad o fiabilidad de las fuentes consultadas. De esta manera, la falta de objetividad también se ha considerado un elemento que quebranta esta máxima.

Se ha estimado que la máxima de la Relevancia no se cumple cuando la temática de las noticias carece de interés para el lector y su cobertura parece no estar justificada por el contexto histórico, social o cultural.

Finalmente, el criterio para el incumplimiento de la máxima de Modo se ha formulado en función de la claridad o carencia de esta que presenta la información. La insinuación y la ambigüedad también se han tenido en cuenta como factores que evitan que la comunicación sea eficaz.

A continuación, se muestran las 26 noticias sobre la cultura española en 2013 y en 2014, cuyo discurso implica un incumplimiento de alguna de las máximas que puede repercutir en la formación de la imagen del país. Estos datos han sido extraídos de un corpus textual sobre noticias sobre España en Theguardian.com (Rodríguez Cuadrado, 2017). Los resultados número de palabras por noticia y contenido aparecen descritos en las siguientes líneas:

(1) From Spain to Eternity review - El Greco's world resurrected with care (número de palabras: 223). En ella se informa de un concierto en la catedral de Toledo para conmemorar el 400 aniversario de la muerte de El Greco.

(2) El Greco in New York review: as good as it gets outside Spain (número de palabras: 1284). Se hacen eco de las celebraciones por la conmemoración del aniversario de la muerte de El Greco.

(3) Falla: Nights in the Gardens of Spain etc. CD review - tepid and undercharacterised (número de palabras: 180). La noticia versa sobre un disco donde el pianista Luis Fernando Pérez interpreta el repertorio de Falla.

(4) Pete Seeger, Woody Guthrie and others: Songs of the Spanish Civil War review - intriguing vintage folk laments (número de palabras: 163). Se centra en las canciones de los brigadistas estadounidenses en la Guerra Civil.

(5) Little-known Spanish singer from the 80s discovers his song is worldwide hit (número de palabras: 560.) Un cantante español de los 80 alcanza el éxito mundial en la actualidad sin recibir el reconocimiento de derechos de autor por parte de las instituciones españolas.

(6) Record-breaking tortilla attempt turns into big embarrassment for Spanish city (Número de palabras: 554). El récord de tortilla está en Japón y no en España. 
(7) Wine: move over Spanish rioja - Argentinian malbec is the new red kid in town (número de palabras: 472). El malbec argentino es considerado superior al Rioja.

(8) Spanish civil war monument must be pulled down, court rules (número de palabras: 396). La noticia trata sobre cómo la justicia española falló a favor de los seguidores del franquismo al ordenar el derribo de un monumento a las brigadas internacionales, cerca del arco de la victoria del bando nacional.

(9) Economic boost? Sephardic Jews contemplate a return to Spain (número de palabras: 1110). El contenido de la noticia es que España ofrece la ciudadanía a los descendientes de los judíos sefardíes expulsados del país por los Reyes Católicos en 1492.

(10) The Spanish language school that delivers lessons on a Budget (número de palabras: 1026). Describen las ventajas y desventajas de la Escuela Oficial de Idiomas (EOI).

(11) I confused my numbers in Spanish - and misreported a death toll (número de palabras: 640). Un reportero cuenta su equivocación con el idioma.

(12) Microsoft's 'Star Trek' Skype translator turns English into Spanish (número de palabras: 223). Microsoft permite a los usuarios de Skype conversar en español mediante el traductor universal de Star Trek.

(13) The Local expands its reach to Spain and Italy (número de palabras: 289). La noticia informa que el sitio web de noticias, The Local, alcanza a España y a Italia.

(14) Flying high with Spain's neon-painted pigeons (número de palabras: 593). La noticia presenta un homenaje fotográfico calificado de "irreverente, surrealista y absurdo", sobre una tradición común en el Levante español.

(15) Spain's everyday internet warrior who cut free from Google's tentacles (número de palabras: 584). Un español que ha pasado los últimos cinco años luchando por el "derecho a ser olvida- do" en Internet aplaude un fallo histórico contra Google.

(16) Spain's newspaper publishers put their faith in 'Google tax' law (número de palabras: 274). Los editores de España han conseguido que comience a tramitar una ley para poder recibir un pago por la apropiación de su contenido en línea.

(17) Spain moves to protect domestic media with new 'Google tax' (número de palabras: 471). Los periódicos en España ahora podrán exigir una cuota mensual del motor de búsqueda antes de poder figurar en Google Noticias.

(18) Google News Spain to close in response to story links 'tax' (número de palabras: 487). Google cierra Google Noticias en España y elimina a los medios españoles del servicio tras una discusión con el gobierno sobre la nueva legislación para proteger a los editores locales.

(19) Google News Spain to be shut down: what does it mean? (número de palabras: 677). Google Noticias se retirará de España antes de que entre en vigor en el próximo año una ley que obliga a los buscadores a pagar a los editores de noticias.

(20) Right to be forgotten is a false right, Spanish editor tells Google panel (número de palabras: 962). Google crea "lagunas de información" y actúa como un "falso fallo judicial sobre un falso derecho" según el editor del Huffington Post.

(21) Google 'plays hardball' in Spanish news row (número de palabras: 533). La amenaza de cerrar Google Noticias en España por la demanda de pago podría ser una táctica de negociación.

(22) Spain's endangered Iberian lynx brought back from brink of extinction (número de palabras: 249). El lince ibérico se recupera de la extinción gracias a un programa de recuperación en Andalucía.

(23) Spain: best budget beach hotels on the Costa Brava and Costa Dorada (número de palabras: 1176). Los mejores presupuestos para hoteles en la Costa Brava. 
Enfoque interdisciplinar del discurso periodístico sobre la cultura española: un estudio del corpus en la prensa digital inglesa

(24) Top 10 budget beach hotels in Andalucía, Spain: part two (número de palabras: 1200). Los mejores presupuestos para hoteles en Andalucía.

(25) 10 of the best family-friendly hotels in Spain (número de palabras: 1545). Los mejores hoteles de España para ir en familia.

(26) 10 of the best family self-catering holidays in Spain (número de palabras: 1745). Los mejores alquileres de vacaciones en familia de España.

\section{DISCUSIÓN DE RESULTADOS}

En líneas generales, los resultados mostraron la importancia de examinar las noticias entendidas como productos culturales y que se categorizan según Symeou, Bantimaroudis y Zyglidopoulos (2015) como cultural agenda setting. Consecuentemente, se ha hecho una correspondencia entre el buen/mal uso de la agenda setting (Tabla 1) y la violación o no de las máximas conversacionales (Tabla 2), lo que ha llevado a deducir si la comunicación entre el medio y lector es eficaz respecto a las noticias culturales analizadas. La cobertura hallada sobre España, según los parámetros de búsqueda establecidos, muestra un total de 49 noticias sobre Cultura. De ellas, en las 26 noticias expuestas anteriormente, se ha observado que se ha producido una posible violación de las máximas.

A continuación, y siguiendo el tercer objetivo propuesto [Medir el proceso de relevancia entre la agenda mediática (causa y efecto) y las máximas conversacionales en las noticias seleccionadas], se presentan las causas de este incumplimiento lingüístico-periodístico (Grice, 1975; McCombs, 2006) y los ejemplos de noticias halladas:

- Falta información (máxima de Cantidad): (3), (4), (8), (12) y (22).

- Exceso de información (máxima de Cantidad): (10), (23), (24), (25), (26).

- Repetición de la temática (máxima de Cantidad): (1), (2), (15), (16), (17), (18), (19), (20) y (21).

- Necesidad de precisar las fuentes (máxima de Calidad): (12), (5).
- Falta importancia o trascendencia (máxima de Relevancia): (6), (10), (11) (13) y (14).

- Relevancia efímera (máxima de Relevancia): (5).

- Ausencia de claridad (máxima de Modo): (12).

- Ausencia de orden (máxima de Modo): (8).

- Insinuación (máxima de Modo): (9).

- No evita la oscuridad de la expresión (máxima de Modo): (14).

- Ambigüedad (máxima de Modo): (7).

Como argumentación adicional, se explican las causas de este desglose siguiendo las pautas reflejadas en el marco teórico (Grice, 1975; McCombs, 1992, 1994, 1996, 2006) y justificado a partir de teoría de análisis del discurso:

(1) y (2) La cuestión se centra en si es necesario informar sobre el 400 aniversario de la muerte del Greco dos veces en un periodo reducido de tiempo (Convoy, 2010; Taylor, 2009; Muñiz 2007).

(3) Hace una crítica a un intérprete de las obras de Falla. Sin embargo, la información es reducida para los lectores que desconocen al compositor (Muñiz, 2007; Matthes, 2006).

(4) Versa sobre las canciones de los brigadistas estadounidenses en la Guerra Civil; tras su lectura se percibe que la cantidad de datos es reducida para su total comprensión (Convoy, 2010; Taylor, 2009; Muñiz, 2007).

(5) No se considera de interés internacional que un cantante español de los años ochenta no haya recibido el reconocimiento ni entendimiento por parte del organismo español que lo gestiona. Asimismo, no se proporciona la opinión de Sociedad de Autores y Editores de España ni de la discográfica y solo se centra en el testimonio del cantante (Muñiz, 2007; Matthes, 2006).

(6) Se considera que una noticia sobre el récord de tortilla española se haya obtenido en Japón y que este hecho haya dejado en ridículo a los españoles carece de interés, además de poseer 
connotaciones negativas hacia los españoles, que son innecesarias (Convoy, 2010; Taylor, 2009; Muñiz, 2007; Lippman, 2003).

(7) El enfoque adoptado está basado en la rivalidad, ya que para informar de un vino deja de forma ambigua que un vino español se está quedando atrás. Puede apreciarse en frases como: "These days, it seems to have ousted even rioja in our affections": En estos días, parece haber expulsado incluso a La Rioja en nuestros afectos (traducido por los autores) (Convoy, 2010; Taylor, 2009; Lippman, 2003).

(8) Se trata de una noticia donde convergen hechos del presente y del pasado. Al estar relacionado con un hecho histórico español, se considera necesario proporcionar más datos, así como un mayor orden para guiar al lector (Muñiz, 2007; Matthes, 2006; Lippman, 2003).

(9) En el texto se sugiere que, si España ofrece la ciudadanía a los judíos sefardíes, expulsados del país en 1492 es por intereses económicos (Convoy, 2010; Taylor, 2009).

(10) La extensión de una noticia sobre la burocracia para estudiar en la Escuela Oficial de Idiomas no se justifica por su relevancia (Muñiz, 2007).

(11) El hecho de que un periodista tenga dificultad en aprender los números en españoles carece de interés (Muñiz, 2007; Matthes, 2006).

(12) Se considera que faltan datos que orienten al lector (Convoy, 2010; Taylor, 2009; Muñiz, 2007).

(13) Noticia no relevante para el perfil de los lectores (Convoy, 2010; Taylor, 2009; Muñiz, 2007).

(14) Para hablar de un libro de fotografía sobre una tradición de palomas en Levante, terminan calificando a España de machista (Matthes, 2006).

(15), (16), (17), (18), (19), (20) y (21) Se ofrece una cobertura sobre el asunto de Google que está injustificada (Muñiz, 2007; Matthes, 2006).

(22) Se dedica poca información (número de palabras) a una cuestión de relevancia y con connotación positiva para una región de España, con respecto a la dedicada a otros asuntos (Convoy, 2010; Taylor, 2009; Muñiz, 2007).

(23), (24), (25) y (26) Ofrecen información turística de manera extensa y de carácter promocional/ publicitario sobre destinos españoles (Convoy, 2010; Taylor, 2009; Matthes, 2006; Lippman, 2003).

En referencia a la máxima de Cantidad, se ha evaluado si la noticia ha sido suficiente informativa o por el contrario, la información ha sido imparcial o ha habido sobreinformación. Este hecho está en correlación con el número de palabras redactadas y al número de veces que ha aparecido su temática. Con respecto al número de palabras, se han determinado tres grupos: noticias con cantidad alta de palabras (más de 1000), aquellas con cantidad media de palabras (entre 500 y 1000) y finalmente, notas con cantidad baja de términos (menos de 500). Consideraremos que la cantidad de palabras empleadas estará en función de la relevancia de la noticia.

En cuanto a la máxima de la Cantidad se observa que la noticia con un mayor número de palabras es la (26), mientras aquella con menor número es la (4). De ello se puede deducir que el establecimiento de la agenda ha tenido en cuenta los posibles intereses de sus lectores en cuanto a los viajes. De ahí que gran parte de la temática de las noticias del grupo 1 esté relacionada con la planificación de las vacaciones [noticias (23), (24), (25) y (26)]. Este hecho les ha dado prioridad respecto a las noticias sobre arte, música o literatura. También merece mención el hecho de que la noticia (10) haya empleado 1026 palabras, cantidad que no parece justificarse en su posible relevancia para el lector inglés al tratarse de la Escuela Oficial de Idiomas, un organismo poco utilizado por estos. Es posible por lo tanto vincular Relevancia y Cantidad y hallar una correlación entre la importancia o trascendencia de la noticia y el número de palabras empleadas.

Por lo tanto, la máxima que incumple en mayor número de ocasiones es la de Cantidad (19 noticias). Asimismo, la violación de la máxima de la Calidad solo se produce en una ocasión. Se observa la falta de Relevancia en cinco ocasiones, mientras que la 
máxima de Modo se ha incumplido en seis ocasiones.

Un resultado interesante de esta medición del proceso comunicativo es la causa y efecto que produce una determinada agenda mediática en el lector, gracias al efecto cognitivo. Son ejemplo de esta cuestión las noticias (5), (9) y (14), por la creación de una posible imagen negativa de España. Estas se enmarcan en la teoría de framing de Muñiz (2007) y Nabi y Oliver (2009).

En cuanto al análisis de los resultados obtenidos promueven la creación de estereotipos/prejuicios y referencias positivas sobre la cultura española, y a su vez ayudan a conocer la representación cultural de España durante 2013 y 2014, años de referencia por la crisis económica en España. Por lo tanto, nos encontramos frente a un proceso de transmisión desde la perspectiva de la agenda mediática (Lazarsfeld y Merton, 1948; McCombs, 2006) y en vista de que es parte del proceso (causa y efecto) por un medio de comunicación como The Guardian y su influencia en la formación de una opinión pública. Estos resultados siguen la línea de los estudios revisados en el estado de la cuestión (Cohen,1963, McCombs, 2006 y Nabi y Oliver, 2009). Son ejemplos de esta influencia e implicación de la opinión pública las siguientes noticias (5), (6), (7), (8), (9), y (14).

\section{CONCLUSIONES}

El objetivo del presente estudio ha sido evaluar la cobertura sobre España y la cultura española en este medio de comunicación británico, con proyección global por su carácter digital per se. Al mismo tiempo, se propuso identificar los aspectos más problemáticos en relación con la implicación y relevancia cultural, y por ende social del lenguaje, a partir de la valoración cuantitativa y cualitativa del discurso. The Guardian selecciona la temática y el lenguaje que emplea, lo que resulta decisivo para la imagen ya que crea una idea precisa en la mente del lector, como ya indicaba Convoy (2010).

Los resultados obtenidos permitieron llegar a una serie de conclusiones que se exponen a continuación. Se ha logrado la identificación y cuantificación de la tipología de las noticias culturales, se ha medido la vinculación entre la agenda mediática y las máximas conversacionales en las noticias seleccionadas, y se ha distinguido la representación cultural de España en este diario durante 2013-2014. Dichas conclusiones generales corresponden a los tres objetivos específicos propuestos.

Asimismo, se ha constatado una correspondencia entre las teorías lingüísticas y las comunicativas tratadas en esta investigación. Esta semejanza se ha observado entre el incumplimiento de las máximas conversacionales formuladas por Grice (1975) y los peligros de un mal uso de la agenda setting. Esto se manifiesta en los siguientes puntos:

(1) El proceso comunicativo no resultaría eficaz si se viola la máxima de la Relevancia; existiría un paralelismo si un medio no presenta una información significativa para el lector.

(2) La violación de la máxima de Cantidad tendría lugar cuando en un diario se produce una ausencia o exceso de información sobre un mismo tema.

(3) La máxima de la Calidad para Grice (1975) estaba vinculada a la veracidad. No hay una Comunicación efectiva si no hay una noticia veraz. La falta de este elemento en la comunicación mediática supondría una mala praxis por parte del medio.

(4) No se debe olvidar el fenómeno de las fake news, cuyas repercusiones pueden ser considerables en todos los niveles. Por último, se ha observado una relación entre la máxima de Modo (referida a la claridad o la ambigüedad) con la información que produzca confusión en el lector. Es preciso subrayar que el periodista, como emisor de un mensaje, en ocasiones puede emplear estos mecanismos de manera encubierta, para llegar a conseguir unos determinados objetivos sobre la opinión de los lectores.

Es importante subrayar también que los resultados del presente estudio de ningún modo pueden generalizarse a contextos culturales y sociales diferentes. La inclusión, en futuras investigaciones, de muestras más amplias y la realización de análisis contrastivos proporcionarían datos de gran utilidad 
para la investigación en este campo. Asimismo, pese a que en la actualidad el Análisis de Sentimiento (Sentiment Analysis) se encuentra en fase de desarrollo, consideramos que esta herramienta, enmarcada dentro de la lingüística computacional, podría tener múltiples aplicaciones para el análisis del discurso periodístico, ya que esta se constituye como una herramienta de clasificación del lenguaje sobre la información subjetiva y puede ser de gran aportación especialmente para aquellos estudios sobre la imagen exterior de un país.

La revisión bibliográfica y el análisis efectuado han permitido constatar los resultados obtenidos y las conclusiones propuestas:

(1) las noticias culturales en este tipo de medios de comunicación ayudan a entender las relaciones socioculturales entre países (comunicación intercultural).

(2) las noticias culturales ayudan a potenciar la imagen cultural de España (perspectiva intercultural).

(3) las noticias culturales producen visibilidad, evolución y transformación dentro de una sociedad de cultura de masas y digital de carácter transversal e híbrido, que potencian los procesos democratizadores de la información (sensibilidad intercultural).

Respecto al contenido de esta investigación es necesario enlazar los efectos de los medios de comunicación y la irrupción del Brexit, que supone la salida del Reino Unido de Europa. Los resultados de este estudio muestran cómo en los años 2013 y 2014 se presentaba a los lectores/opinión pública una visión incompleta, ambigua y con falta de relevancia sobre España que, además, ya había sido bautizada años atrás por la prensa económica británica como un país perteneciente al acrónimo PIGS, para aludir a las economías pobres de Europa. Es inevitable percatarse de las implicaciones que el discurso mediático generó hasta llegar al referéndum del 2016 sobre el Brexit y que está teniendo consecuencias sociales, culturales y económicas hasta la actualidad.

\section{REFERENCIAS BIBLIOGRÁFICAS}

Bell, A. (1996). The Language of News Media. Cambridge, Massachusetts,EE.UU.: Blackwell.

Cohen, B. (1963). The Press and the Foreign Policy. Princeton. EE.UU: Princeton University Press.

Colleen, C. (2010). News talk. Investigating the Language of Journalism. Cambridge. Reino Unido: Cambridge University Press.

Convoy, M. (2010). The language of newspapers. Socio-Historical Perspectives. London; New York: Continuum.

Delgado Gómez-Escalonilla, L. (2012). La acción cultural exterior de España: trayectoria reciente y retos pendientes. En E. Marco Martínez y J. Otero Roth (Eds.). El discreto encanto de la cultura. Nuevas estrategias para la proyección exterior de la cultura, un enfoque práctico (pp. 15-36). Barcelona. España: Ariel.

Fairclough, N. L. (1995). Critical Discourse Analysis: The Critical Study of Language. London, New York: Longman.

Ferrer Montolíu, E. (2014). El Arte un activo para España. La creatividad como variable estratégica en la construcción de la imagen made in. En E. Alonso Pérez, E. Furió, E. Blasco \& E. Sánchez Albarracín (Coords.). Imágenes de España: país, empresas, cultura (pp. 81-92). Oviedo, España: Septem Ediciones.

Fillmore, C. J. (2006). Frame Semantics. En D. Geeraerts (Ed.), Cognitive Linguistics: Basic Readings (pp. 373-400). Berlín. Alemania: Mouton de Gruyter.

Geer, J. (2004). Public Opinion and Polling around the World. Santa Barbara (CA). EE.UU. ABC-CLIO.

Grice, H. P. (1975). Logic and Conversation. En P. Cole \& J. L. Morgan (Eds.). Syntax and Semantics (pp. 41-58). New York. EE.UU: New York Academic Press. 
Enfoque interdisciplinar del discurso periodístico sobre la cultura española: un estudio del corpus en la prensa digital inglesa

Grijelmo, A. (2017). El arte de la manipulación. El País, 22 de agosto. Disponible en https://elpais.com/ elpais/2017/08/22/opinion/1503395946_889112. html

Lazarsfeld, P. y Merton, R. (1948). Mass Communication. Popular Taste and Organized Social Action. En I. Bryson (Ed.). The Communication of Ideas (pp. 229-250). New York. EE.UU.: Harper.

Lippmann, W. (2003). La opinión pública. Madrid, España: Cuadernos de Langre.

Marcos Recio, J. C. (2014). Otra forma de plantear la información y documentación en los medios digitales. Revista General de Información y Documentación, 24(1), 119-134. doi: http://dx.doi. org/10.5209/rev_RGID.2014.v24.n1.45467.

Matthes, J. (2006). The need for orientation towards news media: Revising and validating a classic concept. International Journal of Public Opinion Research, 18(4.1), 422-444. doi: https://doi. org/10.1093/ijpor/edh118.

McCombs, M. (1992). Explorers and Surveyors: Expanding Strategies for Agenda-Setting Research. Journalism Quarterly, 69(4), 813-824. doi: http:// dx.doi.org/10.1177/107769909206900402.

McCombs, M. (1994). The Future Agenda for Agenda-Setting Research. Journal of Mass Communication Studies, 45, 171-181. doi: https://doi. org/10.24460/mscom.45.0_171.

McCombs, M. (1996). Influencia de las noticias sobre nuestras imágenes del mundo. En J. Bryant y D. Zillmann (Eds.). Los efectos de los medios de comunicación. Investigaciones y teorías (pp. 13-34). Barcelona, España: Ediciones Paidós Ibérica.

McCombs, M. (2006). Estableciendo la agenda. El impacto de los medios en la opinión pública y el conocimiento. Barcelona, España: Ediciones Paidós Ibérica.

Meso Ayerdi, K., Mendiguren Galdaspin, I. y Rivero Santamarina, D. (2015). El uso de Storify en la prensa en línea española e inglesa. ¿Añade o elimina valor a la noticia? The Use of Storify and English Online Newspapers. Adding or Removing Value to the News? ICono, 14(13.2), 163-190. doi: https:// doi.org/10.7195/ri14.v13i2.797.

Muñiz, C. (2007). Encuadres noticiosos e inmigración: del análisis de los contenidos al estudio de los efectos mediáticos. Tesis doctoral, Universidad de Salamanca, Salamanca, España.

Nabi, R. L. y Oliver, M. B. (2009). Media processes and effects. Thousand Oaks (CA). EE.UU.: SAGE.

Parodi, G. (2010). Lingüística de corpus: de la teoría a la empiria. Madrid, España: Iberoamericana.

Rius, J. C. (2016). Periodismo en reconstrucción. De la crisis de la prensa al reto de un oficio más independiente y libre. Barcelona: Universidad de Barcelona.

Rodríguez Cuadrado, B. (2017). Análisis sociolingüístico de la imagen de España e Italia en Theguardian.com (2013-2014). Tesis doctoral, Universidad Complutense de Madrid, Madrid, España.

Symeou P. C., Bantimaroudis, P. y Zyglidopoulos, S. C. (2015). Cultural Agenda Setting and the Role of Critics: An Empirical Examination in the Market for Art-House Films. Communication Research, 42(5), 732-754. doi: https://doi. org/10.1177/0093650214534971.

Taylor, C. H. (2009). The Representation of Immigrants in the Italian Press. CIRCaP: Occasional Papers. Università degli Studi di Siena, 21, 1-40. doi: https:// www.circap.org/uploads/1/8/1/6/18163511/ Occ_21_2009.pdf.

Van Dijk, T. (1999). El análisis crítico del discurso. Revista Anthropos, 186, 23-36. doi: http://www. discursos.org/oldarticles/El\%20an\%E1 lisis\%20 cr\%EDtico\%20del\%20discurso.pdf. 